\title{
Congenital nephrotic syndrome responsive to captopril and indometacin
}

\author{
P A J Heaton, O Smales, W Wong
}

\begin{abstract}
Two children with congenital nephrotic syndrome are described (one with Finnish-type nephrosis, the other with diffuse mesangial sclerosis). Both children have had a prolonged and sustained clinical response with good physical health and normal growth patterns using captopril and indometacin as their sole treatment. No adverse effects have been noted. We recommend a trial of indometacin and captopril treatment in cases of congenital nephrotic syndrome. (Arch Dis Child 1999;81:174-175)
\end{abstract}

Keywords: congenital nephrotic syndrome; captopril; indometacin

Congenital nephrotic syndrome of the Finnish type and that caused by diffuse mesangial sclerosis are associated with profound growth failure and death from infection during infancy. Prolonged survival has been achieved by early aggressive medical management, nephrectomy, and renal replacement treatment with dialysis and transplantation. ${ }^{1}$ We report two children with congenital nephrotic syndrome in whom prolonged clinical control has resulted from treatment with captopril and indometacin.

\section{Cases}

CASE 1 (A WHITE GIRL)

Finnish-type nephrotic syndrome was diagnosed histologically in the patient's brother who died at age 6 months. Raised amniotic fluid $\alpha$ fetoprotein concentrations and placental oedema were present, and heavy proteinuria was noted from birth. At age 8 months there was severe growth failure and anasarca. Indometacin $4 \mathrm{mg} / \mathrm{kg} /$ day and captopril $4.5 \mathrm{mg} /$

Taranaki Base

Hospital, Private Bag 2016, New Plymouth 4620 , New Zealand P A J Heaton

Paediatric Department, Hawkes Bay Hospital, Hastings, New Zealand O Smales

Renal Unit, Starship Children's Hospital, Auckland 1, New

Zealand

W Wong

Correspondence to: Dr Heaton. email: paed.cacc@thcl.co.nz

Accepted 17 March 1999

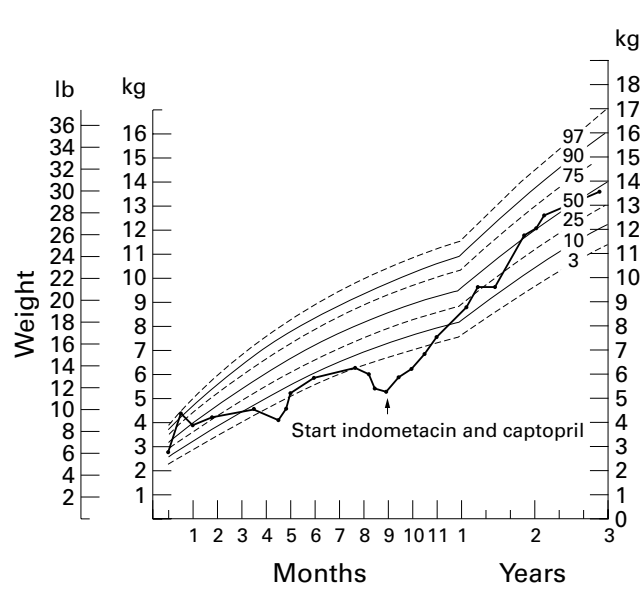

Figure 1 Case 1: effect of treatment on weight. $\mathrm{kg}$ /day were started. There was a rapid diminution of proteinuria and a corresponding rise in serum albumin concentrations. General health improved and no further albumin infusions have been given. At age 4 years she has normal growth (fig 1) and development, and intercurrent infections cause only mild transient oedema. Her sole medication remains indometacin $10 \mathrm{mg}$ twice daily (now $1.5 \mathrm{mg} / \mathrm{kg}$ / day) and captopril (12.5 mg/kg/day).

CASE 2 (A MAORI GIRL)

This patient has healthy unrelated parents, and an uneventful obstetric and family history. She presented at age 10 weeks with pneumococcal meningitis and septicaemia; in addition, proteinuria, hypoalbuminuria, hypomagnesemia, and coagulopathy were noted. Investigations for congenital infections were negative and karyotype was 46XX. Transfusion of albumin at $2 \mathrm{~g} / \mathrm{kg} /$ day was required to maintain serum albumin above $15 \mathrm{~g} /$ litre. Indometacin and captopril were introduced at age 15 weeks and the dosage was increased from $1 \mathrm{mg} / \mathrm{kg} /$ day to $3 \mathrm{mg} / \mathrm{kg} /$ day of each drug as the proteinuria
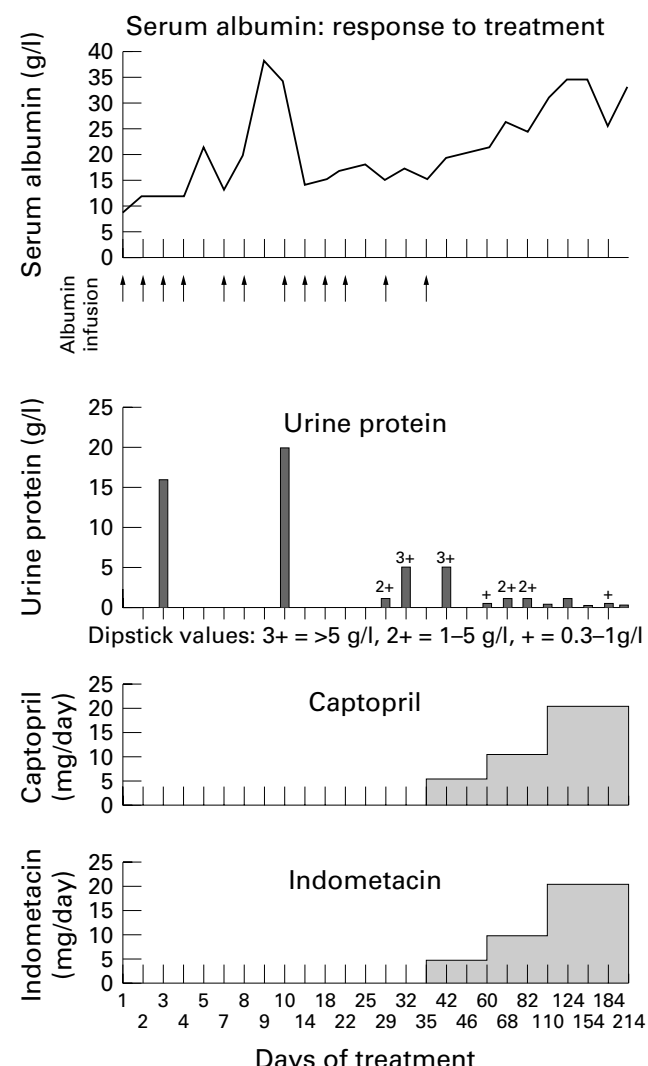

Figure 2 Case 2: effect of treatment on serum albumin and urine protein concentrations. 


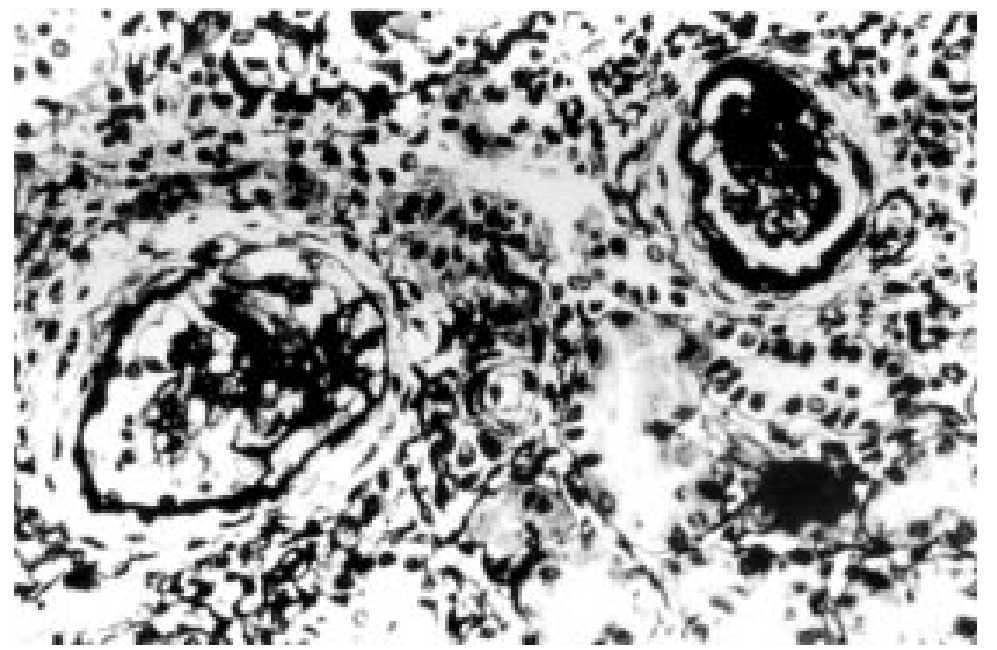

Figure 3 Silver staining of a renal biopsy specimen taken at age 6 months from case 2 . This shows two glomeruli, one completely sclerosed and the other with increased mesangial matrix deposition. The interstitial area shows fibrosis and an increased cellular infiltrate.

decreased and serum albumin rose (fig 2). A renal biopsy at age 6 months showed diffuse mesangial sclerosis (fig 3). At age 20 months she is growing and developing normally and has normal plasma albumin, urea, and creatinine concentrations, with normal urinary protein and creatinine concentrations.

Neither child has experienced any adverse effects or needed albumin infusions since starting on captopril and indometacin.

\section{Discussion}

Pomeranz et al described two infants with Finnish congenital nephrotic syndrome who responded to treatment with captopril (to $5 \mathrm{mg} / \mathrm{kg}$ ) and indometacin (to $4 \mathrm{mg} / \mathrm{kg}$ ). ${ }^{2}$ One child remained well for at least $2 \frac{1 / 2}{2}$ years and the other developed renal failure after about 20 months of treatment. This latter child showed continued responsiveness to treatment, in that proteinuria increased then decreased in response to the cessation then reintroduction of the medication, which was brought about because of concerns regarding the possibility that it was contributing to the glomerular failure. So far, neither of our patients have shown significant reduction of glomerular filtration rate.

Birnbacher et al reported failure of any detectable response to treatment with captopril alone $(0.15-2.5 \mathrm{mg} / \mathrm{kg})$ in an infant with Finnish congenital nephrotic syndrome. ${ }^{3}$ However, Guez et al have documented one child who showed "adequate" clinical control using enalapril alone $(0.75 \mathrm{mg} / \mathrm{kg})$, having commenced treatment using captopril only (to 4.8 $\mathrm{mg} / \mathrm{kg} /$ day). ${ }^{4}$ We are not aware of any reports of this mode of treatment being applied to the management of diffuse mesangial sclerosis.

Although Finnish-type congenital nephrotic syndrome and diffuse mesangial sclerosis result in a similar clinical presentation of severe and usually fatal nephrosis during infancy, the histopathological and molecular genetic features of each condition are distinct. We suggest that the precise pharmacological actions of captopril and indometacin are unknown, but we speculate that activity is effected through microvascular pathophysiological features shared by both Finnish-type congenital nephrotic syndrome and diffuse mesangial sclerosis.

Recently, the locus for Finnish-type congenital nephrotic syndrome was localised to chromosome 19q12-q13.1, through linkage analysis of Finnish families. As yet, our patient with a clinical picture resembling Finnish-type congenital nephrotic syndrome has not had DNA analysis carried out. Fuchshuber and colleagues recently confirmed the linkage of the Finnish-type congenital nephrotic syndrome locus to the same chromosome region as that of affected non-Finnish families, without evidence of dysequilibrium. ${ }^{5}$ Their results show that mutations in the same gene appear to be responsible for the disease in both Finnish and non-Finnish populations. This observation is of interest to us because a considerable number of children with congenital nephrotic syndrome in New Zealand are of Maori racial origin. We are presently undertaking further studies into the genetics of all children with congenital nephrotic children who are still alive in New Zealand.

Pneumococcal septicaemia may occasionally result in an acute glomerulonephritis or haemolytic uraemic syndrome. There were no clinical features in our second patient to indicate that she had either of these conditions. Her urine sediment at presentation showed no haematuria and her serum complement concentrations and blood smear were normal. Furthermore, the renal biopsy was performed at least six months after her acute illness, thus making it extremely unlikely that the diffuse mesangial sclerosis was the result of sepsis. All glomeruli in the biopsy showed varying degrees of mesangial sclerosis, a feature consistent with diffuse mesangial sclerosis.

We believe that this simple and inexpensive treatment has enabled our two patients to enjoy at least one and three years, respectively, of good health and normal growth, although the long term outcome remains unknown. We suggest that newly diagnosed cases of congenital nephrotic syndrome of the Finnish type or nephrotic syndrome as a result of diffuse mesangial sclerosis receive a trial of captopril $(1-5 \mathrm{mg} / \mathrm{kg} / \mathrm{day})$ and indometacin $(1-4 \mathrm{mg} / \mathrm{kg} /$ day).

Presented in part at the XXII international congress of paediatrics, Amsterdam, 1998

The authors thank Dr J Zwi, department of histology, Auckland Hospital, Auckland, New Zealand for reviewing the biopsy.

\footnotetext{
1 Holmberg C, Antikainen M, Rönnholm K, Ala-Houhala M, Jalanko H. Management of congenital nephrotic syndrome of the Finnish type. Pediatr Nephrol 1995;9:87-93.

2 Pomeranz A, Wolach B, Bernheim J, Korzets Z. Successful Pomeranz A, Wolach B, Bernheim J, Korzets Z. Successful
treatment of Finnish congenital nephrotic syndrome with captopril and indomethacin. F Paediatr 1995;126:140-2.

3 Birnbacher R, Förster E, Aufricht C. Angiotensin converting enzyme inhibitor does not reduce proteinuria in an infant with congenital nephrotic syndrome of the Finnish type. Pediatr Nephrol 1995;9:400.

4 Guez S, Giani M, Melzi M, Antignac C, Assael B. Adequate clinical control of congenital nephrotic syndrome by enalapril. Pediatr Nephrol 1998;12:130-2.

5 Fuchshuber A, Niaudet P, Gribouval O, et al. Congenital nephrotic syndrome of the Finnish type: linkage to the locus in a non-Finnish population. Pediatr Nephrol 1996;10:
} $135-8$. 